\title{
Ensayo episódico de la vida internacional de México de 1848 a 1876
}

Episodic essay of Mexico's international life from 1848 to 1876

\section{Fabián Herrera León}

Instituto de Investigaciones Históricas

Universidad Michoacana de San Nicolás de Hidalgo

alcaudon5@icloud.com

Recibido: 15 de enero de 2018 • Aprobado: 10 de febrero de 2018

\begin{abstract}
Cómo citar este artículo: Fabián Herrera León, "Ensayo episódico de la vida internacional de México de 1848 a 1876", en Legajos. Boletín del Archivo General de la Nación, núm. 16 (mayo-agosto 2018), pp. 67-99.
\end{abstract}

\section{Resumen}

El presente artículo fue intencionalmente concebido como una narración de sucesos relativos a la vida internacional de México durante la segunda mitad del siglo XIX, y tiene como propósito introducir al estudio de la historia de las relaciones internacionales. Los referentes bibliográficos que aprovecha son obras de corte general y de reconocidos divulgadores y polemistas del pasado mexicano que inclusive han inspirado la prosa tajante con que está escrito.

Palabras clave: posguerra mexicana, siglo XIX, divulgación histórica, narrativa lineal, historia de las relaciones internacionales

\section{Abstract}

This paper was intentionally conceived as a narrative of events related to the international life of Mexico during the second half of 19th Century, and its purpose is to introduce the study of foreign relations history. The bibliographical references that it employs are well-known oeuvres, some of them written by recognized disseminators and polemicists about the Mexican past, authors who have even inspired the Sharp prose with which this article is written.

Keywords: Mexico Postwar, 19th Century, historical disclosure, linear narrative, foreign relations history 
La historia no es necesariamente lógica, sino a veces tan absurda como los hombres que le fuerzan el rumbo y, sin embargo, el remolino de México, a partir del verano de 1847, colma la medida de lo inverosimil.

José Fuentes Mares, 1982

\section{A modo de introducción}

Uno de los periodos más turbulentos de la historia de México es el que encierra el fin de la guerra con Estados Unidos y el Porfiriato. Corresponden a esos años un destino incierto del país, una paz siempre desafiada por la violencia interior y exterior. Se hace evidente que México, carente de una identidad nacional sólida, es objeto de arrebato de dos mundos muy distintos, que se baten descomunalmente por la supremacía mundial. La pugna entre tradición y liberalismo aborda todas las escalas, se refleja en México y adquiere formas similares. Liberales y conservadores se niegan a ceder en su derecho a forjar un Estado nacional mexicano: su visión de México es contradictoria e invariable. Mientras pelean, son presa fácil de sus aliados morales en el exterior. La solidaridad que otorgan, mínima para cualquier facción, se cobra con creces. Y solo así, a tan duro precio, la identidad y la memoria nacionales se conforman negativamente. El México de la posguerra y el de la República Restaurada son absolutamente distintos hacia fuera, frente al exterior. A la conformación del desastre - que forzó tal cambio en la actitud de México frente al mundo- contribuyeron, por igual, unos y otros, liberales y conservadores. Sustancialmente, su política exterior es la misma: está diseñada para contener al otro, para ganar definitivamente la guerra. Y en esa guerra, por fuerza, se entrometen los aliados, esperando el mejor momento para obtener provecho, para agregar nuevos episodios a la historia y la memoria mexicanas. 


\section{El México de la posguerra: el turno de los moderados}

El 14 de septiembre de 1847, una vez que las tropas norteamericanas se habían apoderado de la capital del país y derrotado a su ejército, Nicholas P. Trist fue comisionado para llevar a México la propuesta de un tratado de paz. A cambio de los territorios de Alta y Baja California, Nuevo México y un derecho de tránsito a perpetuidad por el Istmo de Tehuantepec, Trist ofrecía hasta treinta millones de dólares como indemnización.

Bernardo Couto, Luis Gonzaga Cuevas y Miguel Aristáin fueron nombrados de inmediato para iniciar las negociaciones de paz. Su labor culminó el 2 de febrero de 1848, cuando un tratado de paz, amistad y límites entre México y Estados Unidos fue firmado en Guadalupe Hidalgo. Se hacía oficial la perdida de dos millones y medio de kilómetros cuadrados de territorio mexicano. Nuevo México, Alta California y algunas porciones de los estados de Tamaulipas, Sonora y Baja California pasaban a manos de Estados Unidos en pos del imperio del norte y de su destino manifiesto, que desafortunadamente les había concedido la Providencia para expandir el área de la libertad.

México, por su parte, a modo consuelo, consiguió que el paso entre los dos mares quedara fuera del tratado, obtuvo una compensación económica que de poco le serviría - 15 millones de dólares- y la promesa de una paz firme y universal con Estados Unidos de América.

La bandera de las barras y las estrellas que había hondeado, para colmo, el 16 de septiembre de 1847 frente a Palacio Nacional, fue arriada el 12 de junio del año siguiente y salió del país con las tropas norteamericanas una vez que fue ratificado el tratado de paz.

Las tropas norteamericanas se habían retirado de un país donde reinaría la confusión, el desempleo, el hambre y la eterna deuda con el exterior. La República, intentando dar una imagen de solvencia, destinaba gran parte de la compensación económica al pago de la deuda inglesa. Esta situación provocaría rebeliones y, al poco tiempo, brotes de violencia entre las facciones políticas. Santa Anna, 
condenado por los mexicanos y perseguido por sus invasores, salió al destierro, dejando a los moderados el gobierno de un país más pequeño aunque igual de problemático.

El partido moderado, formado por hombres de los partidos antagónicos - centralistas y federalistas-, influía desde tiempo atrás en los destinos del país. Con Mariano Otero, con Manuel de la Peña y Peña, con otros hombres de patriotismo y temperamento equilibrado, había triunfado el Congreso de 1846. Los moderados fueron favorecidos por una tregua de posguerra entre los partidos fuertes, "como si [apunta Tena Ramírez] se hubieran sentido cohibidos ante el desastre a que habían llevado a la nación".

Los moderados entraron en escena con la presidencia de José Joaquín de Herrera. Desde la independencia de México, Herrera era el segundo sucesor constitucional en la presidencia después de Guadalupe Victoria. A Herrera lo sucedería legalmente Mariano Arista, antes de que se verificase el último gobierno legal del siglo xix en manos de Juárez.

Desde su arribo a la presidencia, Herrera hizo cuanto pudo por reducir los gastos públicos, suprimiendo empleos inútiles y reduciendo el ejército. Sin embargo, pese a todo esfuerzo, con una mala administración y recursos insuficientes, resultado de un sistema hacendario deficiente, resultaba imposible contrarrestar la crisis económica que arrastraba el país. La situación era: muchos acreedores, pocos recursos y la bancarrota.

\section{Tehuantepec: la estrechez inmediata}

El arreglo definitivo de la guerra entre México y Estados Unidos resultó ilusorio. Lo único que se cumplió cabalmente fue la perdida del territorio mexicano. Estados Unidos cumplió con lo menos: no se respetaron las garantías de los mexicanos residentes en el territorio

${ }^{1}$ Tena Ramírez, Derecho Constitucional, p. 26. 
conquistado; ni se evitó la incursión de indios salvajes, desposeídos de sus tierras y empujados hacia el sur; tampoco se cumplió con el pacto de neutralidad para evitar el paso de filibusteros; y, por si fuera poco, se hizo caso omiso a las reclamaciones presentadas por los mexicanos afectados durante la contienda.

Apenas restablecidas las relaciones diplomáticas con Estados Unidos, Tehuantepec volvía a ser tema de discordia. Visto como un paso interoceánico, Tehuantepec puede remontarnos a las expediciones de Cortés. Su historia, en este sentido, cuenta con varios capítulos, siendo los más oscuros los que corresponden a la segunda mitad del siglo xix.

El primero de estos episodios es el de la concesión para la apertura de una vía de comunicación a través del istmo - mediante un camino o ferrocarril que uniera dos puertos sobre ambos mares- otorgada a un contratista privado, José de Garay, en marzo de 1842. Sin embargo, la revolución federalista que derrocó a Santa Anna, y luego la guerra con Estados Unidos, imposibilitaron cualquier trabajo. Ante la proximidad de la guerra con Estados Unidos y el incumplimiento del contratista, el congreso federal declaró caduca la concesión en 1845 .

Durante las negociaciones de paz, Trist recibió instrucciones de negociar los derechos de paso por Tehuantepec, facultándosele a pagar hasta quince millones por ellos. Los comisionados mexicanos declinaron la propuesta, argumentando que los derechos derivados de la concesión de Garay se encontraban ya en poder de los súbditos ingleses Manning, Makintosh y Scheneider. En efecto, Garay había cedido sus derechos a los ingleses el 21 de agosto de 1846, no obstante que la concesión había caducado el año anterior.

Poco después, el 27 de octubre de 1848, Manning, Makintosh y Scheneider facultaron a la firma Hargous Bros., de Nueva York, para que enajenara los derechos y privilegios adquiridos de José de Garay. Así, no obstante la improcedencia legal de cualquier reclamación, Nathan Clifford, por orden del secretario de Estado John Clayton, presentó una protesta. Su sucesor, Robert P. Letcher, consiguió negociar un ambiguo tratado, en enero de 1850, que, sin hacer mención 
de los privilegios otorgados a Garay, resultaba una protección a los intereses titulados a favor de ciudadanos norteamericanos. El tratado que firmaron Letcher y Gómez Pedraza resultó ambiguo, aun para los norteamericanos, que se negaron a ratificarlo porque no reconocía los derechos de los herederos de la concesión de Garay.

La cuestión del istmo había alcanzado tal revuelo que el Congreso reafirmó la caducidad de la concesión de 1842 y de todos los derechos resultantes de la misma, el 22 de mayo de 1851.

El general Mariano Arista, cuya irresponsable actuación en la guerra lo había llevado ante un tribunal, ${ }^{2}$ sucedió a Herrera en la presidencia. Pero ahora no pudo desaparecer para no enfrentar a la reacción de Washington por el decreto de mayo de 1851. La presión de Hargous respecto a la cuestión del istmo decidió al presidente Fillmore a escribir una carta personal a Arista. Fillmore solicitaba la intervención del nuevo presidente para suspender o modificar el decreto del Congreso mexicano, a fin de evitar los riesgos de un nuevo conflicto armado. ${ }^{3}$ Ante tal amenaza, ceder implicaba el peligro de que México se redujera a una cuarta parte de lo que había sido en 1821, y resistir acarrearía la aceptación tácita de una nueva confrontación. La puerta de escape la encontró el canciller José Fernando Ramírez, quien - mediante la diputación de Oaxaca- consiguió que Arista fuera facultado para otorgar al mejor postor - mexicano o norteamericano- una nueva concesión para la apertura de una vía de tránsito por Tehuantepec. Como no se esperaba a ningún concursante mexicano, Arista contestó a Fillmore que en vez de aferrarse a la concesión de Garay - nulificada varías veces-acudiera directamente al gobierno mexicano solicitando una nueva.

Dicha táctica, al final, empeoró la situación: Hargous no cesaría en su empeño, y el gobierno mexicano había otorgado una nueva concesión - el 5 de febrero de 1853- a favor de la compañía formada por el norteamericano A.G. Sloo. Así, sin haberlo previsto, el gobierno mexicano enfrentaría un problema doble.

${ }^{2}$ Vasconcelos, Breve Historia de México, p. 343.

${ }^{3}$ Fuentes Mares, Fuárez, p. 26. 
Mientras tanto, en Jalisco, surgió un plan nacional que pedía el desconocimiento de Arista, la reunión de otro Constituyente y el regreso de Santa Anna. El nuevo plan, elaborado por el santannista Carlos Sánchez Navarro, se conoció como Plan del Hospicio y cundió por todo el país consiguiendo su objetivo: la caída de Arista y el regreso de Santa Anna, después de los interinatos del presidente de la Corte Juan B. Cevallos, y del general Manuel María Lombardini.

Como se consideraba que Santa Anna era el único capaz de restablecer la paz en México se preparó su regreso mediante la convocación a elecciones presidenciales, pudiendo ser candidatos aquellos mexicanos que se encontraban en el extranjero. Una comisión viajó a Cartagena para informar a Santa Anna que había sido electo presidente del país.

Del arribo de Franklin Pierce a Washington no resultó nada benéfico para México. El denominador común de las sucesivas administraciones estadounidenses de la época siguió siendo el expansionismo territorial. Poco importaba el cambio de personas o de partidos al frente del gobierno, todos coincidían en sus proyectos imperiales, salvo en el caso del tratado McLane-Ocampo, negociado con el bando liberal encabezado por Juárez en plena Guerra de Reforma. Entre 1795 y 1898, concluye José Fuentes Mares, "Estados Unidos remató el edificio cuyos cimientos echó la dinastía de virginia. Persuadidos de su divina elección y ejemplaridad, o lo que es lo mismo de su superioridad, los angloamericanos ejercieron durante ese lapso, colectivamente, la mística del expansionismo". ${ }^{4}$ Una vez conformes con los resultados de su expansión territorial hacia 1898, Estados Unidos haría modificaciones en su política exterior propias de un imperialismo comercial. ${ }^{5}$

Antes de que todo esto ocurriera, James Gadsden era designado ministro en México, por intervención de Jefferson Davis, entonces secretario de Guerra y, posteriormente, presidente de los Estados Confederados de América. De las instrucciones de rigor otorgadas al nuevo

${ }^{4}$ Fuentes Mares, Génesis del expansionismo, p. 255.

${ }^{5}$ LaFeber, "Un momento crucial", p. 85. 
ministro, el 15 de julio de 1853 figuraban, en primer lugar, la de recordar a México que los derechos derivados de la concesión de Garay seguían en sus manos, y, en segundo lugar, que en beneficio del comercio debía cederse a Estados Unidos el territorio necesario para construir un ferrocarril que correría del río Grande al Pacífico. ${ }^{6}$

Sólo en Washington podían sentirse enteramente complacidos con el regreso de Santa Anna, a quien le habían tomado la medida desde que fue descubierto y apresado en Texas. En este sentido, Pierce y Jefferson Davis trabajaban en la gloria de su administración a costa del territorio mexicano. Así, a cinco años del gran cercenamiento, se ocupaban de dibujar en el mapa cuatro líneas posibles para la nueva frontera con México. Con lo menos que podía conformarse Pierce, en caso de que el gobierno mexicano rehusara las cuatro fronteras trazadas, era con el terreno suficiente para correr una línea ferroviaria desde la desembocadura del río Bravo hasta las costas del Pacífico, junto con la liberación de las obligaciones impuestas a Estados Unidos por el Artículo xi del tratado Guadalupe Hidalgo, consistentes en la vigilancia y defensa fronteriza contra las tribus nómadas y belicosas del área. A cambio de estas peticiones, Gadsden estaba facultado para ofrecer a México la cantidad de quince millones.

Los distintos planes concebidos por Pierce y Davis llegaron a Gadsden por medio de Christopher L. Ward, un abogado apoderado de los intereses de Hargous. Cumplió con esta tarea, pero no sin antes agregar a las instrucciones de negociación los derechos de tránsito por Tehuantepec, lo cual derivó en una pugna con Gadsden. El asunto de Tehuantepec y de la concesión de Garay podían entorpecer las negociaciones en torno a una nueva frontera, lo cual hizo saber el ministro a William L. Marcy, encargado del Departamento de Estado. Marcy estaba de acuerdo con Gadsden en no mezclar ambas cuestiones. Sin embargo, Gadsden incluyó el problema del istmo durante dos distintas conferencias con los comisionados mexicanos. El termino de esas negociaciones llevó a la firma del Tratado de La mesilla el

${ }^{6}$ Fuentes Mares, Fuárez, p. 30. 
30 de diciembre de 1853, en el cual, para frustración de Ward y de Gadsden, no figuró Tehuantepec.

El penúltimo de los más importantes capítulos sobre el istmo se concretiza en la firma del Tratado McLane-Ocampo del 14 de diciembre de 1859. Un año antes de que esto ocurriera, México inició a sus adentros la guerra más enconada y honda de su historia, en que dos partidos irreductibles -liberales y conservadores- se disputaron a muerte la dirección y el futuro del país, todo ello producto de la revolución de Ayutla, que embarcó a Santa Anna en el "Iturbide", es decir, a su último exilio.

Durante el primero de los tres años que duró la guerra, las victorias estuvieron a favor de los conservadores, pero al siguiente se equilibraron, por lo que ambos bandos buscaban desesperadamente la definición. Juárez - cabeza de los liberales- la buscaría al otro lado del Bravo, donde había sido reconocido en abril de 1859. Tiempo atrás, el bando liberal venía solicitando un préstamo a Estados Unidos para ganar la guerra. Sin embargo, le fue negado en varias ocasiones, aun cuando fue reconocido como el gobierno legítimo de México, a fin de que Juárez cediera la Baja California, al calor de la fiebre del oro. ${ }^{7}$ Cuando Juárez consideró que la situación era crítica accedió a negociar con Estados Unidos un tratado en torno a Tehuantepec.

Mediante el tratado firmado el 14 de diciembre de 1859, México cedía a Estados Unidos, a perpetuidad, el derecho de tránsito por el istmo de Tehuantepec, por cualquier camino existente o por existir, además los derechos de tránsito entre la ciudad de Guaymas a Nogales, y de Camargo a Matamoros, por el río Bravo al puerto de Mazatlán por la vía de Monterrey. Para proteger esas vías de tránsito, proporcionaría México los servicios militares necesarios, y solo en caso de que el gobierno mexicano lo solicitara ejercerían esa protección las tropas estadounidenses. Pero se convino algo más, y esta es la peor parte del acuerdo: "en el caso excepcional de peligro imprevisto o inminente para la vida o propiedades de Estados Unidos", su fuerza militar quedaba autorizada para actuar en protección de sus nacionales sin

${ }^{7}$ Galeana, México y el mundo, pp. 98-99. 
el consentimiento previo del gobierno mexicano. A cambio de todo se pagarían cuatro millones en compensación, aunque Juárez sólo contaría con dos para terminar la guerra, pues el resto se abonaría a la deuda de México con Estados Unidos por concepto de reclamaciones. Krauze, a modo de paradoja, refiere:
Ocampo, el hombre que en 1847 había pugnado por la guerra de guerrillas, el mismo que había clamado al cielo por la destrucción del país antes que verlo dominado por los angloamericanos concertó, con aprobación de Juárez, la entrega parcial de la soberanía mexicana a cambio de apoyo económico y militar contra los conservadores. ${ }^{8}$

Afortunadamente, Juárez no recibió nada, y definiría su victoria por otros medios, pues el tratado no fue ratificado por el Senado norteamericano, ante la inminente guerra entre esclavistas y antiesclavistas. Pero no todo se perdió. Antes del rechazo legislativo del tratado, Juárez consiguió derrotar a Miramón y con ello vencer en la Guerra de Reforma.

Miramón había tendido cerco por tierra a Veracruz. Para completarlo, había contratado en La Habana dos vapores españoles de guerra que bloquearían el puerto. Enterado de todo ello, Juárez se dirigió a McLane, solicitando la intervención de Estados Unidos como si el tratado estuviera ratificado. Los barcos y corbetas norteamericanas capturaron al Marqués de La Habana y al General Miramón, cuando atracaron en Antón Lizardo, bajo el pretexto o la razón de considerarlos piratas, y luego remolcarlos a Nueva Orleáns. Sin el esperado apoyo naval fracasó la estrategia conservadora. Miramón, sin saberlo, había perdido la Guerra de Reforma, lo cual quedaría confirmado nueve meses después, el 22 de diciembre, en Calpulalpan.

El conflicto de intereses por el istmo de Tehuantepec cesó hasta el 13 de abril de 1937, cuando el secretario de Estado Cordell Hull y el embajador de México en Washington, Francisco Castillo Nájera, suscribieron una convención derogatoria de las obligaciones contraídas por México sobre las posibles vías de tránsito en Tehuantepec, poniendo así punto final al controvertido tema. 


\section{La Mesilla}

Fue Lucas Alamán el impulsor intelectual del regreso de Santa Anna a México en 1853. Alamán tenía ideas encontradas sobre el general. Lo veía como un hombre de lucha e imaginación, a pesar de sus cualidades negativas. Había colaborado algunas veces con él y al final de su vida lo haría decididamente, confiado en que con su poder directo, incuestionable, Santa Anna resultaba ser la única posibilidad de un gobierno enérgico y fuerte. Se impusieron a Santa Anna las condiciones en que debía ejercer la dictadura durante un año, mientras se reunía un nuevo Constituyente. En abril de 1853 el dictador publicó las "Bases para la administración de la República, hasta la promulgación de la Constitución", que refrendaban los ministros Alamán, Lares, Tornel y Antonio Haro y Tamariz, destacadas figuras del partido conservador. Durante este gobierno, Alamán ocupó por última vez la Secretaría de Relaciones Exteriores. Pero su gestión fue muy breve, pues murió de pulmonía a poco más de un mes de sustentar el cargo.

La muerte de Alamán y la destitución de Haro y Tamariz frustraron los propósitos del partido conservador para organizar constitucionalmente el país. Santa Anna quedó solo, entregado, por debilidad, al desenfreno, exaltada igualmente su vanidad, que lo llevo a aceptar oficialmente el mismo título que ostentó Hidalgo en Guadalajara, el de Su Alteza Serenísima, ${ }^{9}$ y olvidado de Constituyentes y Constituciones.

Del último gobierno de Santa Anna - que fue el undécimo-, destacan dos acontecimientos en materia de política exterior: el primero, que fue el último capítulo de la guerra con Estado Unidos, la perdida del territorio de La Mesilla; el segundo, la gestión para instaurar en México un trono con un príncipe europeo.

En agosto de 1853 se instaló en México el nuevo ministro de Estados Unidos, James Gadsden, a quien en octubre, como ya hemos referido, se le instruyó para negociar el establecimiento de una frontera "más

${ }^{7}$ Krauze, Siglo de caudillos, p. 184. 
lógica y ventajosa" entre ambos países, y liberar a Estados Unidos de las obligaciones contraídas en el Artículo xi del Tratado Guadalupe Hidalgo. Esta nueva oferta de compra obedecía a que se construiría un ferrocarril transcontinental desde la desembocadura del Bravo hasta las costas del Pacífico, y como la línea fronteriza estorbaba, lo más lógico para los hombres del "destino manifiesto", era recorrerla hacia el sur.

La negación del gobierno mexicano a negociar derivó en la concentración de tropas norteamericanas en la frontera. ${ }^{10}$ Como no parecía haber escapatoria a las miras de Washington, y a fin de que no se repitiese la historia texana en los seis estados fronterizos, incluyendo Baja California, Santa Anna nombró a Díez de Bonilla -su ministro de Relaciones Exteriores- para que, en compañía de José Salazar Ylarregui y Mariano Monterde, discutiera las propuestas norteamericanas, con la intención de ceder lo menos posible. De entre cinco propuestas, que no eran más que líneas trazadas en un mapa en forma de nuevas posibles fronteras, la menos avariciosa era la concerniente al territorio fronterizo conocido como La Mesilla, por el que estaban dispuestos a pagar hasta quince millones.

El 30 de diciembre se firmó el Tratado Gadsden o de "La Mesilla" que ponía fin al periodo de despojos territoriales y que resolvía tres cuestiones fundamentales: la primera, los Estados Unidos quedaban eximidos de sus obligaciones conforme al Artículo xi del Tratado Guadalupe Hidalgo, que eran las de vigilar y contener las incursiones de los indios bárbaros sobre la frontera mexicana; la segunda, México cedía el territorio limítrofe con Sonora y Chihuahua por el que atravesaría el ferrocarril transcontinental norteamericano; y, la tercera, Estados unidos asumía las reclamaciones de ciudadanos estadounidenses presentadas entre el 2 de febrero de 1848 y el 30 de diciembre de 1853, incluyendo las reclamaciones de la concesión de Garay. Sin embargo, esta última parte fue retirada del tratado por petición de Pierce antes de que se presentara para su debida ratificación.

${ }^{10}$ Galeana, México y el mundo, p. 63. 


\section{El trono imperial}

Al desembarcar Santa Anna por última vez, llegaba con el proyecto de restaurar el Plan de Iguala, que había traicionado en 1822 proclamando la República. Sin embargo, el proyecto de restauración sufriría dos golpes sucesivos: el primero, la muerte de Lucas Alamán; y el segundo, el empeño del pueblo mexicano en coronarlo como a Iturbide. Desde antes de que se hiciera cargo del país, habían empezado los pronunciamientos en diversos lugares, todos dirigidos a la elevación de Santa Anna al trono. Como hemos mencionado, el general supo conformarse con ser Su Alteza Serenísima. Pero, tras la firma del Tratado de la Mesilla, no era aventurado suponer que con los practicantes del destino manifiesto en un Norte cada vez más cercano, México dejaría de existir en poco tiempo, de no contar con el respaldo de alguna nación poderosa. En este sentido, Santa Anna autorizó el 1 de julio de 1854 a José María Gutiérrez Estrada, un diplomático nacido en Campeche -antiguo federalista en los años veinte- a gestionar, con plenos poderes el establecimiento de una monarquía en México, derivada de alguna de las casas dinásticas francesas, españolas o austriacas. Gutiérrez Estrada sentía tanto odio por Estados Unidos que en 1940 llegó a proponer, como solución a todos los males que aquejaban al país:

Que la nación examinara si la forma monárquica, con un príncipe de estirpe real, no sería más acomodada a las tradiciones, a las necesidades y a los intereses de un pueblo que desde su fundación fue gobernado monárquicamente. Si no variamos de conducta, quizá no pasaran veinte años en que veamos tremolar la bandera de las estrellas norteamericanas en nuestro Palacio Nacional. ${ }^{11}$

${ }^{11}$ Krauze, Siglo de caudillos, p. 157. 
No pasaron ni diez años para que se hiciera realidad tan triste augurio, pero para ensayar a un príncipe en México se requirió de más tiempo y del desarrollo de algunas circunstancias que finalmente lo hicieron posible. Mientras todo esto ocurría, el descontento frente al gobierno de Santa Anna fermentaba en todo el país. Los conservadores con Haro y Tamariz y los moderados con el gobernador de Guanajuato, Manuel Doblado, se ponían de acuerdo para arrojar a Su Alteza Serenísima del poder. Pero la revolución que lo propiciaría nació en Ayutla.

Un pronunciamiento contra el gobierno a mediados de 1853 en la Costa Chica de Guerrero había sido sofocado con anterioridad por el cacique de la región, el viejo liberal Juan N. Álvarez. Dada la muestra del poder absoluto y poco fiable de Álvarez, Santa Anna dispuso la remoción de empleados civiles y militares. Igualmente, pretextando un posible ataque del filibustero Walker, ${ }^{12}$ envió tropas de confianza a Acapulco para contrarrestar la fuerza de Álvarez.

El primero de marzo de 1854 la guarnición del pueblo de Ayutla en el estado de Guerrero proclamó en un plan el desconocimiento de Santa Anna - acusado de falsear "en su espíritu y objeto el Plan de Jalisco", de oprimir al pueblo recargándolo de contribuciones onerosas

${ }^{12}$ El oro encontrado en la Alta California desencadenó una ola de peligro dirigida por los filibusteros hacia el Sur. En diciembre de 1853 el filibustero norteamericano William Walker pretendió crear la República de Sonora y Sinaloa e invadió La Paz. Se estableció en Ensenada y se dedicó al asalto a rancherías. Fue derrotado por tropas mexicanas en mayo de 1854. Sin embargo, se le consignó a la Corte de Estados Unidos y fue absuelto. Ya no volvió a México, pero en Nicaragua se autoeligió presidente, contando con el beneplácito norteamericano hasta que fue derrocado por los países centroamericanos en 1857. A sonora llegó el conde francés Gastón de Rousset-Boulbon en julio de 1854, al mando de cuatrocientos aventureros. Solicitó fallidamente la autorización de Santa Anna para colonizar la región. Fue apresado y fusilado el 12 de agosto de 1854 por orden de Santa Anna después de atacar los cuarteles mexicanos en Guaymas. Una incursión más de esta naturaleza la dirigió el norteamericano Eulogio Gautier Valdomar en Tamaulipas, entre agosto y septiembre de 1854. Logró apoderarse de Ciudad Victoria, y escapó después de su derrota. Al respecto, véase Fabela, Buena y mala vecindad, pp. 100-144; también en Galeana, México y el mundo, pp. 73-74. 
y de enriquecer a sus favoritos- y la convocatoria de un Congreso Constituyente. Poco después, el 11 de marzo, el Plan de Ayutla fue secundado en Acapulco por el coronel retirado Ignacio Comonfort con algunas reformas, entre las cuales figuraba la de que sería el Constituyente quien decidiera acerca de la forma federal. Santa Anna intentó inútilmente sofocar la sublevación que encabezaban, además de Comonfort, Álvarez, Tomás Moreno y Florencio Villarreal.

Si bien durante algunos meses el levantamiento en Guerrero fue visto como otro más, al tiempo creció en fuerza y en adeptos, entre ellos, los liberales puros, por quienes se modificaría el plan, que ahora consideraba a las instituciones liberales como las únicas que convenían al país.

Los proscritos del gobierno de Santa Anna, refugiados en Nueva Orleans, entre los que se encontraban dos gobernadores que no simpatizaron con Su Alteza Serenísima, Melchor Ocampo, de Michoacán y Benito Juárez, de Oaxaca, emprendieron el regreso.

Temiendo Santa Anna que la revolución le cortara la retirada, se embarcó al exilio el 16 de agosto de 1855. Con él, cabe señalarlo, se clausuraba la etapa de los generales mercenarios al servicio -indistinto- de los partidos.

Al triunfo de la revolución, y después del interinato de Álvarez, previsto en el Plan de Ayutla, llegó a la presidencia Ignacio Comonfort, quien trataría a la vez de sofocar la reacción del clero, la del no disuelto ejército santannista y de contener el programa del partido de la reforma, encabezado por los ministros Juárez, Ocampo y Prieto. Durante el gobierno de Comonfort se suprimió la Compañía de Jesús y en junio de 1856 se emitió la Ley Lerdo con el propósito de hacer circular las propiedades raíces del clero, exceptuando aquellas que sirvieran directamente a la Iglesia: conventos, hospitales y casas de beneficencia, así como las tierras de cultivo necesarias para su sostenimiento.

\section{El Pontificado: el Concordato o el despojo}

La situación política del país había entrado en una crisis tan aguda que llevaría a la liquidación de una época, lo que despertó al máximo la 
defensa de los intereses secularmente consagrados. De entre ellos, había uno amenazado como nunca antes: el de la Iglesia. "Dada la influencia de la Iglesia católica [según dijo Santa Anna a Poinsett cuando era prisionero en Texas], el despotismo es el único gobierno aconsejable, pero no hay razón para que este despotismo no sea sabio y virtuoso". ${ }^{13}$

En 1821, México se había independizado de España pero no del orden colonial, pues el lugar histórico de la Iglesia católica seguía siendo central. A la influencia espiritual del clero correspondía un poder económico y político de primer orden. Pero no siempre fue así. En virtud de los derechos del Patronato, que en favor de los reyes de España reconoció Julio II en 1508, la Corona hizo las veces de jefe de la Iglesia con independencia casi absoluta de Roma. De este modo, se eludía el peligro de que el gran poder de la Iglesia tratara de enfrentarse al poder civil. Sin embargo, una vez que México consiguió su independencia, el vínculo que unía y sometía a la Iglesia al Estado se rompió automáticamente. El gobierno mexicano sostuvo reiterada, aunque inútilmente - hasta antes de Ayutla-, el derecho a suceder en el Patronato al monarca español.

La gravedad que se derivaba de la falta de ese vínculo estribaba en que quedaban sin definir las medidas y las condiciones en que la Iglesia y sus hombres se subordinaban civilmente al Estado mexicano. Es decir, como lo explica Tena Ramírez,

[que] los cuantiosos bienes del clero estaban exentos de toda coacción civil, además de que en el aspecto económico esos bienes vinculados a instituciones permanentes quedaban fuera de todo comercio. Otra facultad del Estado, que también se detenía ante el Sagrado de la Iglesia, era la jurisdiccional en materia civil y penal, pues el clero tenía sus tribunales propios. ${ }^{14}$

${ }^{13}$ Krauze, Siglo de caudillos, pp. 143-144.

14 Tena Ramírez, Derecho Constitucional, p. 30. 
Todo esto hacía que la Iglesia, independizada del Estado al abolirse el Patronato, constituyera un Estado dentro de otro Estado. Aunque, considerando que el poderío moral y económico de tal organización era muy superior al del gobierno, siempre en quiebra y carente de prestigio, puede decirse, más bien, que se trataba de Estados paralelos. Como sea, para que el poder civil pudiera ganar el terreno perdido frente a la Iglesia podía elegir entre dos caminos: el primero, restaurar el Patronato, que en la colonia sirvió para resolver el problema; o, el segundo, someter al clero mediante nuevas leyes universales, es decir, mediante una legislación común. El primero lo caminaron sin éxito los gobiernos conservadores, a diferencia de los liberales que se empeñaron en seguir el segundo después de la Revolución de Ayutla.

Puede decirse que casi todos los gobiernos que se sucedieron en el México independiente hasta 1861 enviaron o mantuvieron una representación en Roma para conseguir que se aceptara la firma de un nuevo concordato. Sin embargo, dicha petición fue negada una y otra vez, pese a que el Estado mexicano siempre había declarado a la religión católica como única. Por lógica, al triunfo de la reforma liberal, la representación y un mejor entendimiento con Roma dejaron de ser necesarios..$^{15}$

El embrionario Estado liberal tenía que disputar fatalmente con ese Estado interior o paralelo. Y el 23 de noviembre de 1855 el gobierno de Comonfort inició la ofensiva reformista al expedir la Ley Juárez, que suprimía el fuero eclesiástico y el militar en los negocios civiles. Al comenzar el año siguiente, después de una sangrienta rebelión de los conservadores, Comonfort intervino los bienes del obispado de Puebla y se emitió la Ley Lerdo, con el propósito de hacer circular las propiedades raíces del clero. ${ }^{16}$

El 18 de febrero de 56 se instaló el Congreso Constituyente, formado por una mayoría de moderados y una minoría de radicales,

\footnotetext{
${ }^{15}$ Galeana, México y el mundo, p. 72.

${ }^{16}$ Galeana, México y el mundo, p. 81.
} 
designados todos por los gobernadores. La Constitución de 1857 consignó la supresión completa de fueros eclesiásticos; negó a las corporaciones civiles o eclesiásticas la capacidad para adquirir o administrar bienes raíces, pero no consagró la tolerancia religiosa ni se refirió para nada a la separación del Estado y la Iglesia.

En cuanto a las relaciones entre sí de los poderes, la Constitución de 1857 entregó al Ejecutivo en manos del Legislativo por un justificado temor a la dictadura. Al poco tiempo de promulgada, Comonfort se dio cuenta de que con ella no se podía gobernar en paz -lo cual confirmarían Juárez y Lerdo de Tejada después-, debido a sus disposiciones reformistas y a la limitación de su poder, por lo cual decidió derogarla. A fines de 1857, Zuloaga proclamó el Plan de Tacubaya, en virtud del cual cesaba de regir la Constitución y se ordenaba la convocación de un nuevo Constituyente. El presidente aceptó el plan; el Congreso Constitucional protestó y se disolvió. Un mes más tarde, Zuloaga se rebeló contra Comonfort, justo cuando quería dar marcha atrás, consiguiendo su destitución. Los conservadores nombraron presidente a Zuloaga y quedaban dueños de la capital.

Una vez liberado de su aprisionamiento en Palacio Nacional, Benito Juárez asumía sobre la base de la Constitución de 1857 la presidencia de la República y el mando de los liberales. Comenzaba la guerra entre liberales y conservadores, que no fue impedimento para que la obra de la Reforma continuara. Sin esperar a que cesara la guerra, el gobierno de Juárez completó la obra de la Reforma, aunque las nuevas leyes fueran irrealizables. El 12 de junio de 1859 se decretó la más radical de todas, la nacionalización, sin compensaciones de ninguna clase, de los bienes del clero; siguiéndole la que declaraba la separación de la Iglesia y el Estado. Se decretaba, pues, la independencia absoluta del poder civil.

\section{Proyectos de paz}

Eran muy pocos los que tenían una idea fiel del horror que comprendía la guerra entre mexicanos. Aquellos que desde un principio habían 
contemplado la muerte continua de sus hombres desearon más que ninguno la paz y la tranquilidad para el país. La diferencia real era -más allá de ser liberal o conservador-: los que hacían la guerra y los que no, o, si se quiere, los que veían a sus hombres morir y los que simplemente hacían restas en un papel. Tal vez sea esa la razón por la cual Santos Degollado y Miramón, haciendo a un lado su necedad, pensaron y propusieron medidas que llevaran la guerra a su fin.

Hacía 1859, Santos Degollado se reunió con Miramón en los ranchos de la Calera y del Rayo con el fin de llegar a un acuerdo en este sentido. La solicitud que Miramón rechazó fue la de que aceptara el orden constitucional. Poco después, otra proposición reveladora del deseo de paz que compartían los jefes militares fue hecha por Miramón durante el segundo sitio de Veracruz, una vez capturados sus buques. Sin embargo, las propuestas que hizo Miramón a los constitucionalistas de poco sirvieron ante el regocijo de los liberales al haber ganado una batalla. Se habían puesto a consideración de Juárez las siguientes medidas: celebración de un armisticio para convenir la manera de restablecer la paz en la República; intervención en las pláticas, como mediadores amigables, de los representantes de Inglaterra, Francia, España, Prusia y Estados Unidos; ninguno de los partidos podría celebrar tratado alguno con potencias extrañas sin la intervención y consentimiento del otro; finalmente, una asamblea, compuesta de los funcionarios que hubieran desempeñado en la República los puestos públicos de mayor jerarquía - de 1822 a 1853- elegiría presidente provisional de la República, fijaría las bases que debía observar la administración provisional y quedaría encargada de redactar la Constitución, la cual no debería regir hasta que fuese aprobada por la mayoría de los ciudadanos mexicanos. ${ }^{17}$ Paradójicamente, a Degollado, quien había sustituido a Ocampo en Relaciones después de la firma del Tratado McLane-Ocampo, le tocó declinar la propuesta con argumentos validos, más no por ello insensatos.

${ }^{17}$ Fuentes Mares, Miramón, el hombre, pp. 87-88. 
Más tarde, aunque ya no se dudaba del triunfo liberal, Degollado estaba convencido de que un triunfo por las armas solo conduciría a una pacificación momentánea e injusta. Pensaba en un plan de pacificación que respetara las leyes de Reforma, pero que no obstruyera las modificaciones que necesitaba la Constitución. En una carta dirigida el 21 de septiembre al representante de Su Majestad Británica, George W. Mathews, Degollado exponía estas inquietudes. Pero no era todo. Su propuesta de que se instalara una junta compuesta por los miembros del cuerpo diplomático residente en México para nombrar un presidente provisional hasta que se instalara el Congreso de la Unión, le valió el desprecio de Juárez y de todo el grupo liberal. Lo anterior fue suficiente para que el jefe militar más importante durante la guerra, el paladín liberal, fuera destituido, apresado y sometido a juicio por ordenes de Juárez. A Juárez y su comitiva, es cierto, les asistía la ley, pero no el derecho. La cabeza del bando liberal era un idólatra de la ley, mas nunca, como afirma Fuentes Mares, "comprendió el Derecho, que es el resorte de justicia trascendente que presta espiritualidad a la ley y le da sentido humano". ${ }^{18}$ Alcanzado el triunfo, Degollado pelearía su reivindicación, al conseguir la autorización del Congreso para vengar el asesinato de Ocampo. Innecesariamente, con su muerte, Degollado se ganaba el lugar que le correspondía entre los hombres de bronce de la historia de México.

\section{Intervención e Imperio (1861-1863)}

El primero de enero de 1861, Juárez, en calidad de presidente y líder del bando liberal, entró victorioso a la Ciudad de México. De inmediato ordenó la expulsión del representante español junto con los de Guatemala, Ecuador y del Vaticano, acusándolos de haber intervenido en los asuntos internos del país. Aunque no fueron los únicos, sí eran los más débiles e innecesarios para el gobierno liberal.

${ }^{18}$ Fuentes Mares, ...y México se refugió en el desierto, p. 68. 
Con un país destruido por la guerra y con un erario en quiebra total, Juárez se vio obligado a declarar el 17 de julio de 1861 la moratoria de dos años en el pago de sus obligaciones con el exterior.

En la tarde del 25 de julio, las legaciones de Francia e Inglaterra arriaban sus respectivas banderas: acaba de expirar el plazo que Charles Lennox Wyke -ministro inglés-y Dubois de Saligny -ministro francés-, fijaron de común acuerdo para que Juárez derogara el decreto y cumpliera con sus obligaciones.

El decreto del 17 de julio proporcionó a las potencias europeas un casus belli más o menos legítimo para intervenir, circunstancia agravada por los conservadores mexicanos residentes en Londres y Madrid, pero sobre todo en París, donde encabezaba la camarilla mexicana el hacendado José Manuel Hidalgo, amigo íntimo de Napoleón y de la Emperatriz, la granadina Eugenia de Montijo. ${ }^{19}$ Al lado de Juan N. Almonte y Gutiérrez Estrada, Hidalgo consiguió interesar a Napoleón, al tiempo que se trabajaba coordinadamente en arrastrar a España y Gran Bretaña para intervenir en México. Completaba el grupo de los monarquistas mexicanos Francisco de Paula y Arrangoiz, un antiguo representante de México en Washington que cobró para sí el 10\% del pago por la compra de La Mesilla en $1854 .{ }^{20}$ Napoleón admitía como representantes de la voluntad de México a estos pocos que enarbolaban la bandera monarquista, pero ello no era suficiente. Un momento coyuntural lo propició todo.

Cuatro días después de publicarse el decreto, los soldados de la Unión Americana perdieron la batalla de Bull Run frente a los ejércitos confederados. Así las cosas para los autores de la doctrina Monroe, el gobierno liberal de Juárez se encontraba más solo y desprotegido que nunca, pues por nada del mundo se le ocurriría a los unionistas salir a la defensa de la libertad, arriesgando su situación interna y propiciando que alguna potencia europea se aliara o comerciara abiertamente con

\footnotetext{
${ }^{19}$ Fuentes Mares, Juárez, pp. 239-241.

${ }^{20}$ Galeana, México y el mundo, pp. 63-64.
} 
los esclavistas. Mientras la Guerra de Secesión durase, las potencias europeas se encontraban libres para emprender todo tipo de aventuras en América Latina. ${ }^{21}$ Sin embargo, nada podía hacerse en contra de la voluntad de Gran Bretaña, pero Su Majestad Británica estaba dispuesta a sumarse a la empresa.

El día 31 de octubre de 1861 Gran Bretaña, Francia y España -con viejas y nuevas reclamaciones contra México- firmaron la Convención de Londres, y sus propósitos fueron: ocupar los puertos mexicanos y forzar el pago de las deudas contraídas por México con las tres potencias.

Francia reclamaba por la suspensión de pagos a la deuda francesa, por daños hechos a sus nacionales y por la falta de reconocimiento y pago de los bonos Jecker. ${ }^{22}$ Gran Bretaña, por su parte, exigía satisfacciones por la suspensión de pagos a su deuda, como por la sustracción de seiscientos sesenta mil pesos, en depósito y bajo la protección de la legación británica en México, por obra del gobierno conservador, así como la suma de cuatrocientos mil pesos, tomada por Degollado de la conducta de Laguna Seca. España por último, reclamaba también por la suspensión de pagos a su deuda, y, fundamentalmente, por haber desconocido el gobierno mexicano el tratado que celebraron en París Alejandro Mon, en representación del gobierno español, y Juan

${ }^{21}$ Boersner, Relaciones internacionales, p. 121.

${ }^{22}$ Juan B. Jecker, fundador de la casa Jecker, De la Torre y compañía, llegó a México en la primera mitad del siglo xIx. Su negocio comercial se mezclaría en varias actividades ilegales y subversivas, como la invasión del filibustero francés, el conde Gastón de Raousset-Boulbon, al estado de Sonora en 1854; pero su mayor fraude consistió en el contrato que el 29 de octubre de 1859 firmó con Isidro Díaz, secretario de Hacienda del gobierno de Miramón mediante el cual se emitieron bonos por valor de quince millones al seis por ciento anual durante cinco años. A cambio, Miramón recibió setecientos veintitrés mil en efectivo y cuatrocientos sesenta y ocho mil en equipo y vestuario. Juárez, al ocupar la capital en enero de 1861, declaró nulo y sin efecto el contrato y expulsó a Jecker del país. Éste se estableció en Francia, obtuvo su naturalización y se asoció al duque de Morny, hermano de Napoleón III, con cuya influencia consiguió que el emperador incluyera el cumplimiento de ese contrato entre las reclamaciones que en 1862 desencadenaron la guerra. Enciclopedia de México, pp. 461-462. 
N. Almonte por parte del gobierno conservador mexicano, que incluía reparaciones por los daños causados a sus súbditos en México. Cabe hacer un paréntesis para tratar sobre este tratado.

Justo en el momento del ascenso liberal en 1856, los conflictos entre terratenientes y comunidades indígenas tocaron fondo, dando lugar a la violencia de unos contra otros. El 15 y 16 de septiembre de ese año, en el mineral de San Dimas, Durango, la población atacó y saqueó el establecimiento de los españoles Juan y Andrés del Castillo. Tres meses después, el choque racial derivó en ataques contra las haciendas de Chiconcuac, San Vicente y Dolores, en Morelos, propiedad del terrateniente Pío Bermejillo. El saldo de este enfrentamiento fue el saqueo, la muerte de media docena de españoles y la ruptura de relaciones entre México y España. ${ }^{23}$ Por el Tratado MonAlmonte, firmado el 26 de septiembre de 1859, el gobierno conservador mexicano se comprometía, básicamente, a tres cosas: perseguir y castigar a los cómplices y asesinos de San Dimas; indemnizar a las familias de las víctimas de Chiconcuac, San Vicente y San Dimas; y, por último, a restablecer la Convención que en 1853 celebraron Antonio López de Santa Anna y el representante español, el marqués De la Ribera, reconociendo obligaciones de México por siete y medio millones de pesos frente a España. ${ }^{24}$

Pero volvamos a 1861; el acuerdo tripartito se empezó a materializar el 15 de diciembre, cuando la fuerza expedicionaria española compuesta por 5600 hombres desembarcó sin oposición en Veracruz y, de inmediato, se puso a administrar su aduana. El 7 de enero de 1862, llegó su comandante, el general Prim, conde de Reus y marqués de Castillejos con 734 soldados más. Hasta después aparecerían los ingleses con 700 royal marines y los franceses con 2400 hombres.

El primer obstáculo que encontró la intervención tripartita, y más aun, el proyecto de Napoleón, fue haber desembarcado en Veracruz,

\footnotetext{
${ }^{23}$ Meyer, El cactus y el olivo, pp. 54-55.

${ }^{24}$ Galeana, México y el mundo, pp. 90-91.
} 
una ciudad exaltadamente liberal, donde, como señala Bulnes, "hasta los españoles eran republicanos". ${ }^{25}$

En un primer momento, Juárez optó por negociar, considerando que España sería la potencia más interesada en aprovechar la coyuntura para solucionar por la fuerza su conflicto con México; y antes había creído que sería la única potencia intervensionista. ${ }^{26}$

Sin embargo, desde que Prim desembarcó, aseguró que no venía a ninguna reconquista, sino a reafirmar los términos de los acuerdos firmados en 1853, el pago de compensaciones por los asesinatos de españoles en las haciendas de Morelos y en el mineral de San Dimas, más el envío de un representante a Madrid para dar una cumplida satisfacción a la reina por la expulsión del embajador José Joaquín Pacheco. Cuando resultó evidente que Napoleón III sí deseaba iniciar una operación política de gran envergadura en México - desalojar del poder a los liberales e imponer como jefe a un monarca austriaco ligado a Francia-, Prim tomó la decisión de reembarcar su contingente en abril de 1862.

Inglaterra, recibida la seguridad de que la moratoria sobre los compromisos mexicanos con el exterior estaba anulada, también se retiró y a partir de ese momento la aventura europea en México fue solo francesa.

Rompiendo con todos sus compromisos, los franceses avanzaron sobre territorio mexicano rumbo a la capital. Para 1864, el ejército francés y las tropas conservadoras casi habían vencido a los liberales. Tras la derrota de Puebla, Juárez se trasladó a San Luis Potosí, iniciando su peregrinar por el Norte mexicano. Volvería a la capital cuatro años después.

Antes del arribo de Maximiliano de Habsburgo a México, el comandante en jefe del ejército francés, general Forey, consiguió empañar, para sorpresa de todos, las relaciones con la Iglesia. Si bien afirmaba que

${ }^{25}$ Bulnes, El verdadero fuárez, p. 8.

${ }^{26}$ Fuentes Mares, ...y México se refugió en el desierto, p. 53. 
la iglesia católica sería protegida, anunciaba que el futuro Emperador vería con placer establecer la libertad de cultos, y que la ley de nacionalización de bienes eclesiásticos debería prevalecer. ${ }^{27}$

Por su parte, el gobierno republicano se abocó a organizar la resistencia. Necesitaba armamento y el único lugar para adquirirlo era Estados Unidos. Como se recordará, la situación para los unionistas no era la mejor. El gobierno norteamericano se vio forzado a declarar su neutralidad respecto a México.

Por los Tratados de Miramar, Maximiliano aceptaba obligaciones económicas y políticas importantes frente a Napoleón III antes de dirigirse a su imperio mexicano. El naciente imperio debía pagar anualmente a Francia cantidades exorbitantes por concepto de gastos de la expedición francesa desde 1864, además de indemnizaciones y deudas añejas. Por los artículos secretos de Miramar, el futuro emperador se comprometía a cumplir con los lineamientos liberales de gobierno que había anunciado Forey, y a mantener un contingente militar francés cada vez más reducido.

Una vez en México, Maximiliano provocó el desaliento de los conservadores, debido a que su primer gabinete quedaba conformado por una mayoría de liberales moderados. Por si fuera poco, Maximiliano envió fuera del país a los generales más distinguidos del conservadurismo, a fin de mantenerlos al margen y evitar cualquier oposición a su política liberal. Miramón, el "macabeo", fue enviado a Berlín a estudiar -irónicamente- técnicas de artillería, mientras que Leonardo Márquez ocupaba la representación del imperio en Estambul.

Así, desde un primer momento, resultaba evidente que Maximiliano no parecía entenderse con la Iglesia ni con los conservadores.

El segundo imperio contó con la aceptación de toda Europa, aunque no así de América, donde solo Brasil y Guatemala reconocieron a Maximiliano.

Entre los objetivos de la política exterior del imperio figuraban: lograr un concordato con el Pontificado para ejercer el Regio

${ }^{27}$ Galeana, México y el mundo, p. 164. 
Patronato y obtener el reconocimiento de Estados Unidos, único -aunque ambiguo- apoyo con que contaba Juárez.

La relación de Maximiliano con la Iglesia se deterioró aun más cuando el Papa Pío IX envió a Francisco Meglia como nuncio apostólico ante el imperio, con el fin de firmar el añorado concordato. Meglia venía instruido para exigir el restablecimiento del culto bajo el régimen de religión única; la reposición de las ordenes monásticas; el derecho de las autoridades eclesiásticas a supervisar la educación pública; y, finalmente, el restablecimiento del patrimonio de la Iglesia. Maximiliano respondió con un proyecto de concordato de nueve puntos, que implícitamente ratificaría las Leyes de Reforma: tolerancia para todos los cultos, aunque dando tratamiento de religión de Estado a la católica; sostenimiento de los ministros católicos por cuenta del Estado; eliminación de derechos parroquiales, diezmos, primicias y dispensas, y cesión al gobierno imperial de los derechos que aún tuviera la Iglesia sobre bienes nacionalizados durante la República. El nuncio, naturalmente, se negó a firmar el concordato. El regreso de Meglia a Roma tras la ruptura de las negociaciones dejó un sabor amargo a la Iglesia y a los conservadores. ${ }^{28}$

Pese a todo disgusto, Maximiliano puso en marcha una serie de medidas reformistas que deterioraron por completo la situación: dispuso la nacionalización de bienes eclesiásticos y suprimió el pago de las observaciones parroquiales; prohibió la publicación de la Encíclica Pontificia que condenaba la libertad de cultos, la formación de Estados laicos y el principio de soberanía de los pueblos; decretó la libertad de cultos y de prensa; organizó el registro civil; y, por último, pretendió convertir a los sacerdotes en asalariados al servicio del Estado. ${ }^{29}$

Mientras Maximiliano se enfrentaba a la Iglesia, Juárez se decidía por la dictadura, maniobrando para contener la presidencia más allá del 30 de noviembre de 1864, fecha que marcaba el fin de su mandato.

\footnotetext{
${ }^{28}$ Galeana, México y el mundo, pp. 186-187.

${ }^{29}$ Galeana, México y el mundo, p. 188.
} 
Hacia 1865 la situación favorecía a los ejércitos franceses y a Maximiliano frente al gobierno constitucional, pero la guerra civil norteamericana llegaba a su fin con el triunfo de los unionistas sobre los esclavistas. Ya no existía impedimento para que los Estados Unidos se ocuparan de la cuestión mexicana. Se consideraba como prioridad para la seguridad nacional de Estados Unidos hacer desaparecer la amenaza monárquica del continente. Una vez desempolvada la doctrina Monroe, el gobierno norteamericano permitió la exportación de armas al gobierno constitucional, además de otorgarle un préstamo de casi tres millones de dólares para su adquisición. ${ }^{30}$ Juárez comenzó a recibir auxilios de armas, dinero y hombres. Por toda la frontera surgieron ejércitos liberales. La balanza se inclinó a su favor, permitiéndoles resistir y dar el tiro de gracia al Segundo Imperio.

La presión diplomática norteamericana sobre Francia, acompañada de la amenaza del general Grant de invadir México ${ }^{31}$ y del peligro bélico que suponía la unificación alemana dirigida por Bismarck, determinaron el retiro de las tropas francesas de suelo mexicano. Del resto se encargarían las fuerzas republicanas, que a partir de marzo de 1866 consiguieron una serie de triunfos que las llevaron a Querétaro en mayo de 1867.

Fue demasiado tarde cuando Maximiliano, vuelto al proyecto conservador, solicitó a Miramón y a Márquez que reorganizaran el ejército imperial, mientras la Emperatriz Carlota gestionaba inútilmente el auxilio de Francia, Austria y Roma.

El episodio final del imperio daría nuevos matices a la visión de Europa sobre México. Se dijo, y se dice todavía, que con el fusilamiento de Maximiliano, Juárez quiso hacer entender a las potencias imperiales que México había ganado por segunda vez su independencia.

Tras el regreso de Juárez a la capital, México vivió aislado del mundo europeo. Al principio, la Republica Restaurada contaría

\footnotetext{
${ }^{30}$ Galeana, México y el mundo, p. 200.

${ }^{31}$ Fuentes Mares, Biografia de una nación, pp. 203-204.
} 
únicamente con el reconocimiento de Estados Unidos y el de las otras repúblicas americanas - con excepción de Brasil y Guatemala que habían desconocido al gobierno republicano a favor del imperio. De momento, los liberales no sintieron necesidad de restablecer sus relaciones con Europa, posponiendo el momento de la difícil renegociación de deudas y reclamaciones. Juárez estaría dispuesto a reanudar sus relaciones con los países europeos que reconocieron al imperio, siempre y cuando tomaran la iniciativa y aceptaran la negociación nuevos tratados, pues los anteriores, en justicia, ya no tenían validez para México.

Juárez ya no era el mismo que había vuelto a la capital en 1861. Entendía que la soberanía nacional no residía en el exterior o en los diplomáticos, quienes en México tenían la vieja costumbre de vender su reconocimiento. La visión de Bulnes en torno a estos diplomáticos resulta muy ilustrativa:

Eran las grandes locomotoras del agio en México y los mejores órganos para el descrédito de las naciones en que operaban y para la gestión de convenciones, bombardeos, bloqueos, ultimátum e invasiones. ${ }^{32}$

Lamentablemente, para México, la "doctrina Juárez" no aplicaba con los Estados Unidos. En agosto de 1869, antes de abandonar la misión diplomática en Washington, Matías Romero firmó con el secretario de Estado, William H. Seward, una convención para integrar una comisión mixta de reclamaciones entre ambos países. Una vez instalada, el trabajo fue lento y las resoluciones pocas, lo cual permitió que se acumularan cada vez más reclamaciones norteamericanas de dudosa autenticidad. De entre ellas, las más notorias fueron la de Weil y de la Abra y la del Fondo Piadoso de las Californias. ${ }^{33}$

32 Bulnes, El verdadero Juárez, p. 18.

${ }^{33}$ Galeana, México y el mundo, p. 225. 
Los cambios políticos en Europa permitirían, si no la reanudación de relaciones con México, algunos acercamientos, después de que Isabel II y Napoleón in fueran derrocados. Los nuevos gobiernos de España y Francia no se oponían a la reanudación, siempre y cuando, se reconocieran las reclamaciones pendientes.

La presencia del general Prim al frente del gobierno español en 1868 facilitó dicho fin. Aunque existía entre ambos gobiernos una identificación ideológica, lo cierto era que España temía la independencia de Cuba. Los trámites de la reanudación quedaron en suspenso por el asesinato de Prim, pero, al poco tiempo, el rey de España envió a México a Feliciano Herreros de Tejada como enviado extraordinario y ministro plenipotenciario ante el gobierno de Juárez. Herreros venía a negociar la estricta neutralidad del gobierno mexicano frente a Cuba, por lo cual aceptó esperar dos años para tratar sobre cualquier reclamación española frente a México. Convenido lo anterior, las relaciones se reanudaron de inmediato. ${ }^{34}$

$\mathrm{Al}$ establecerse la Tercera República Francesa encabezaban el gobierno aquellos que se habían opuesto a la aventura imperial en México. Mas no por ello el restablecimiento de las relaciones entre México y Francia resultaba cosa fácil, pues el gobierno mexicano lo condicionaría al pago de los daños causados al país durante la intervención. ${ }^{35}$ La reanudación fue posible 10 años más tarde, cuando el gobierno Porfirio Díaz asumió una actitud más flexible y conciliadora, conviniendo ambas partes en desconocer antiguos tratados y reclamaciones. ${ }^{36}$

Gran Bretaña, que no había sufrido ningún cambio en su gobierno, sería la última potencia europea con quien México reanudó sus relaciones, ya que Su Majestad Británica se mostraría renuente a dar el primer paso exigido por Juárez. El restablecimiento fue posible hasta 1885, también durante el gobierno de Díaz. ${ }^{37}$

\footnotetext{
${ }^{34}$ Galeana, México y el mundo, p. 230.

${ }^{35}$ Galeana, México y el mundo, p. 231.

${ }^{36}$ Lajous, México y el mundo, pp. 122-129.

${ }^{37}$ Lajous, México y el mundo, pp. 130-133.
} 
Hacia 1871, solamente España, Italia y la Confederación Alemana mantenían relaciones con el gobierno republicano.

Por segunda ocasión, Sebastián Lerdo de Tejada y Porfirio Díaz presentaron sus candidaturas para relevar a Juárez en el ejercicio presidencial. Sin embargo, por segunda ocasión, también, Juárez resultaba reelecto, aunque esta vez no llegaría al final de su mandato. A su muerte - el 18 de julio de 1872- Lerdo de Tejada lo sucedió en la presidencia.

La política exterior del nuevo presidente no sufrió modificaciones frente a Europa. No obstante, se verificarían algunos cambios substanciales en otras áreas. Bajo la dirección e iniciativa de José María Lafragua, la política exterior mexicana fue dirigida al desarrollo de vínculos mercantiles y comerciales para reanimar el desarrollo económico del país. ${ }^{38}$ Por su puesto, los resultados no fueron los esperados, pero dicho objetivo trascendió a una nueva etapa.

Igualmente, el periodo que comprende la República Restaurada fue suficiente para ensayar los cimientos de la política exterior tradicional, al llevarse a la práctica los conceptos que México sustenta como principios constitucionales en dicha materia: no intervención, autodeterminación de los pueblos e igualdad de las naciones.

Los años que transcurrieron de 1867 a 1876, "lucen -en palabras de Luis González- como aurora de un día de la vida de México conocido con los nombres de porfirismo y porfiriato, que fue inicialmente porfirismo por la adhesión popular a Porfirio, y después porfiriato por la adhesión de don Porfirio a la silla presidencial". ${ }^{39}$

\section{A modo de cierre}

Al final de la guerra con Estados Unidos, México se vería obligado a transigir frente a las presiones externas, al pago de sumas exageradas

${ }^{38}$ Galeana, México y el mundo, p. 247.

${ }^{39}$ González, "El liberalismo triunfante", p. 652. 
y negociaciones ruinosas. Con un territorio cercenado a la mitad adquirieron fuerza diversas concepciones políticas de gran alcance para solucionar la situación del país en los planos interior y exterior. Los conservadores considerarían útil mantener buenas relaciones con Europa, los liberales preferirían estrechar las relaciones con Estados Unidos. Los dos partidos fuertes de México tendrían que enfrascarse en una lucha a muerte para imponer su proyecto. Fue una batalla que venía de tiempo atrás, que nunca dejo de librarse, pero que tras la Revolución de Ayutla tendría que ser definitiva. El vigor de unos y de otros alcanzó niveles insospechados. Sin embargo, la guerra se ganaría de la mano de Estados Unidos y no de Europa. Después de la batalla de Calpulalpan, del indiscutido triunfo liberal, México volvió a la normalidad, es decir, a la inestabilidad política. La apremiante situación económica de un país incapaz de afrontar su deuda externa y el desvanecimiento momentáneo de la doctrina Monroe, fue para los conservadores su última oportunidad. Sin embargo, ya no tenían opciones, más que la de vincular sus intereses a los de los monarquistas y a los sueños de un imperio mexicano de Napoleón III. Los conservadores lograron el apoyo europeo para neutralizar la alianza liberal con Estados Unidos, pero el apoyo francés ahogaba al Imperio. Tras el fin de la Guerra Civil Norteamericana, el apoyo de Washington resultó fundamental para que los liberales se sobrepusieran a la alianza -cada vez más difícil- de los conservadores con los franceses y se viniera abajo el II Imperio que encabezó Maximiliano de Habsburgo.

Una verdadera estabilidad para el país vino con la restauración de la República. Juárez y Lerdo de Tejada, con el respaldo de su fuerte relación con Estados Unidos, pudrían posponer -indefinidamente- la negociación de las deudas del país con Europa. 


\section{Fuentes}

\section{Bibliografía}

Boersner, Demetrio, Relaciones internacionales de América Latina. Breve historia, Caracas, Nueva Sociedad, 1996.

Bulnes, Francisco, El verdadero Juárez y la verdad sobre la intervención y el imperio, México, Ediciones Ateneo, 1989.

Enciclopedia de México, t. vII, 1977.

Fabela, Isidro, Buena y mala vecindad, México, América Nueva, 1958.

Fuentes Mares, José, Biografia de una nación. De Cortés a De la Madrid, México, Océano, 1984.

, Génesis del expansionismo norteamericano, México, Grijalbo, 1985.

, Fuárez: los Estados Unidos y Europa, México, Grijalbo, 1981. , Miramón, el hombre, México, Joaquín Mortiz/Contrapuntos, 1978. ,...y México se refugió en el desierto. Luis Terrazas: historia y destino, México, Centro Librero La Prensa, 1987.

Galeana, Patricia, México y el mundo. Historia de sus relaciones exteriores, vol. III, México, Senado de la República, 2000.

González, Luis, "El liberalismo triunfante", en Historia General de México, México, El Colegio de México, 2000, pp. 635-705. 
Krauze, Enrique, Siglo de caudillos. Biografía política de México (1810-1910), México, TusQuets Editores, 1994.

LaFeber, Walter, "Un momento crucial: los años de McKinley (18961900)", en Victor Adolfo Arriaga Weiss y Arturo Grunstein Dickter (comps.), Estados Unidos visto por sus historiadores, t. II, México, Instituto Mora/Universidad Autónoma Metropolitana, pp. 52-85.

Lajous, Roberta, México y el mundo. Historia de sus relaciones exteriores, vol. Iv, México, Senado de la República, 2000.

Meyer, Lorenzo, El cactus y el olivo. Las relaciones de México y España en el siglo xx, México, Océano, 2001.

Tena Ramírez, Felipe, Derecho Constitucional, México, Porrúa, 1944.

Vasconcelos, José, Breve Historia de México, México, cecsa, 1977. 